\title{
How Does The Urban-Rural Income Gap Affect Regional Environmental Pollution? --Re- Examination Based On The Experience Of Cities At Prefecture Level And Above In China
}

\author{
Weiwei He ( $\nabla$ 124039791@qq.com ) \\ Hunan University https://orcid.org/0000-0001-9182-9612 \\ Junjun Hou \\ Hunan University \\ Keke Cheng \\ Hunan University
}

\section{Research Article}

Keywords: Urban-rural income gap, regional pollution, consumption scale, human capital, spatial correlation, environmental regulation

Posted Date: March 3rd, 2022

DOI: https://doi.org/10.21203/rs.3.rs-1338786/v1

License: (c) (1) This work is licensed under a Creative Commons Attribution 4.0 International License.

Read Full License 
1 How does the urban-rural income gap affect regional

2 environmental pollution?

8 School of Economics and Trade, Hunan University, Changsha, Hunan,

\section{at prefecture level and above in China}

\author{
Weiwei He*, Junjun Hou, Keke Cheng
}

China

10

12 Abstract: Based on the traditional "EKC" theory, this paper re-examines

13 the impact of urban-rural income disparity on regional pollution and its

14 mechanism by using panel data of Chinese cities at prefecture level and

15 above from 2005-2015, combining demand scale and human capital

16 perspectives. The results show that the urban-rural income gap has a

17 significant "inverted U-shaped" trend on urban pollution. Both the scale

18 of demand and human capital are the main mechanisms influencing the 
19 environmental pollution effect of urban-rural income gap, and the 20 marginal pollution effects of both are "first negative and then positive"

21 along with the widening of urban-rural income gap. The pollution effects

22 of urban-rural income disparity have significant spatial correlation both

23 nationally and within regions. The intensity of environmental regulations

24 is an important factor affecting the urban-rural income gap, and has a

25 significant "positive U-shaped" effect on regional pollution through the 26 urban-rural income gap.

27 Keywords: Urban-rural income gap, regional pollution, consumption scale, 28 human capital, spatial correlation, environmental regulation

29 JEL: P25, Q52, R23

\section{Introduction} has achieved sustained and rapid growth for more than 40 years. Its GDP ranks second in the world and its industrial output value has long been

35 the world's largest newly industrialized country. China's rapid economic growth has comprehensively improved the material living standards of residents, but it has also brought about a series of environmental 
38

39

40

41

42

43

44

45

46

47

48

49

50

51

52

53

54

55

degradation. As residents' awareness of environmental protection

continues to increase, coordinating economic development and

environmental protection has gradually become a hot issue of Chinese

society. According to World Bank statistics, China's total carbon dioxide

emissions in 2014 were approximately 10.29 billion tons, more than six

times that of 1.46 billion tons in 1978 , with an average annual growth

rate of over $5.5 \%{ }^{(1)}$. Especially since 2013 , large-scale haze weather has

swept across China, which has adversely affected the work and life of

residents. The report of the 19 th National Congress of the Communist

Party of China pointed out: "The modernization that China wants to build

is a modernization in which man and nature coexist in harmony. It is

necessary to create more material wealth and spiritual wealth to meet the

people's growing needs for a better life, but also to provide more high -

quality ecological products to meet the people's growing needs for a

beautiful ecological environment $"{ }^{(2)}$. This requires China to transform

the past extensive economic model, promote supply-side adjustments,

further release the reform "dividends", and strive to cultivate emerging

growth points to cope with the "new economic normal" faced by the

\footnotetext{
Data Sources: Word Bank Open Databas

(2) Source: "China Statistical Yearbook" over the years
} 
country.

As a traditional economic hotspot, the issue of income disparity has emerged in China across urban and rural areas, regions, industries, and gender. Among them, as China's economic growth and industrial expansion have caused drastic changes in the urban and rural economic structure, the "dualization" of the urban and rural economy and the negative role of the urban-rural income gap in China's economic development have become increasingly prominent, and have gradually become a long-term focus of public opinion. The National Bureau of Statistics pointed out that from 2000 to 2019 , the ratio of per capita disposable income of urban and rural residents in China fell from 2.78 to 2.64, while the income gap between urban and rural residents widened from 4,000 yuan to 26,000 yuan ${ }^{(3)}$. Facts show that although the relative income gap between urban and rural residents in China has been slightly converging since the 21 st century, the absolute income gap between urban and rural residents has shown a clear divergence. In other words, the problem of urban and rural income inequality is still very prominent in China at this stage. Income inequality will not only cause great

\footnotetext{
(3) Source: "Outline of the 13th Five-Year Plan for the National Economic and Social Development of the People's Republic of China"
} 
74 obstacles to regional growth and industrial upgrading but also derive

75 many social problems such as public security and law, which will

76 directly hurt residents' daily lives. The "13th Five-Year Plan" issued by

77 the Chinese Central Government in 2016 emphasized that "industry

78 nurturing agriculture, cities nurturing rural areas, and improving the

79 integration of urban and rural development" are currently the key areas

80 for China to explore new driving forces for economic growth and

81 industrial transformation ${ }^{(4}$. Because urban-rural income gap and

82 environmental pollution are both key issues related to the current

83 economic growth and industrial transformation in China, a

84 comprehensive and systematic discussion of the interactive relationship

85 between the urban-rural income gap and environmental pollution is of

86 positive significance for supplementing and improving the theoretical

87 system of the income gap and environmental pollution research, guiding

88 and helping the formulation of regional industrial policies. Therefore,

89 based on the existing research conclusions, this article attempts to re-

90 discuss the actual impact of the urban-rural income gap on environmental

\footnotetext{
(4) Source: "Outline of the 13th Five-Year Plan for the National Economic and Social Development of the People's Republic of China"
} 
91 pollution from the perspective of traditional supply and demand theory,

92 and further analyze the mechanism path of its impact. the urban-rural income gap on environmental pollution. First, Grossman and Krueger (1991) and Panayotou (1993) pointed out that there is an environmental Kuznets curve (EKC) between per capita income and environmental pollution. However, because per capita income indicators cannot reflect the income differences between different income groups, this makes EKC theory is difficult to reasonably explain the actual impact of income disparity on environmental pollution. Scholars such as

101 Coondoo and Dinda (2008) believe that it is income disparity rather than income level that affects environmental pollution; secondly, more studies

103 have discussed the impact of regional Gini coefficient on local

104 environmental pollution, but this is different from the urban-rural income 105 gap; then, there are also some controversies about the actual interaction 106 between income gap and environmental pollution. Some scholars believe 107 that the income gap and environmental pollution are linearly related 108 (Ghalwash, 2008; Baek and Gweisah, 2013), while other scholars believe 109 that the two should show a non-linear correlation (Scruggs, 1998; Yang 110 Qian and Liu Huajun, 2012); finally, the existing researches have a lot of 
111 controversies about the impact mechanism of income gap on

112 environmental pollution. Although the research objects are involved in

113 income levels (Vona and Patriarca, 2011), human capital (Shen Kunrong

114 and Geng Qiang, 2001), and environmental policies (Yu Xiangyu et al.,

115 2019), the content is often scattered and difficult to explain the current

116 problems comprehensively and reasonably. In other words, there is still a

117 lack of a unified understanding of "how the income gap, especially the

118 income gap between urban and rural areas, affects environmental

119 pollution" and "what is the mechanism for the impact of urban-rural

120 income gap on environmental pollution". Therefore, from the two

121 dimensions of demand and supply, the impact of the urban-rural income

122 gap on environmental pollution and its impact mechanisms are re-

123 organized, and the logical core of the environmental pollution impact of

124 China's urban-rural income gap is further explored. This is not only

125 conducive to dissolving China's urban-rural dual economic structure, but

126 also an important guarantee for China's industrial transformation and the

127 promotion of the "Industry" 2025 plan. Compared with the existing

128 literature, the marginal contribution of this article lies in:

First, this article discusses the actual impact of China's urban-rural

130 income gap on local environmental pollution and integrates the two 
131 dimensions of the demand side and the supply side to separately examine

132 the impact path of the urban-rural income gap on environmental

133 pollution. Urban-rural income distribution and environmental protection

134 are both important topics in my country's economic research at this

135 stage. Existing research mainly focuses on the inflection point of income

136 level in the process of environmental pollution effects of the urban-rural

137 income gap, therefore, combining the two perspectives of demand and

138 supply to scientifically comb the relationship between the two will not

139 only broaden the existing urban-rural income gap assessment perspective

140 but also deepen the awareness of improving the regional environment

141 and fostering new driving forces for industrial growth.

Second, this article takes the lead in researching the urban-rural

143 income gap and environmental pollution in cities at the prefecture level

144 and above. Existing literature research objects are mainly concentrated

145 on the transnational (Han Jiabin and Han Mengying, 2015) or trans-

146 provincial (Zhan Hua, 2016) level. This article re-examines the actual

147 impact of the urban-rural income gap on environmental pollution from

148 the level of prefecture-level and above cities. It is not only a further

149 investigation of the actual impact of China's urban-rural income gap on

150 China's environmental pollution but also a scientific basis for 
151 governments at all levels to accurately formulate environmental policies.

152 Third, this paper uses the most detailed urban-rural permanent

153 population and its actual income data. Since the 1980 s, the cross -

154 regional migration of China's population has accelerated. Compared with

155 the registered population, the local permanent population can more

156 objectively reflect the size and structure of the local population. In the

157 context of incomplete urban-rural data at the city level in the current

158 various data statistics, this paper manually searches, merges, and

159 calculates the urban-rural income gap in 270 prefecture-level and above

160 cities in China from 2005 to 2015 , which reflects in more detail the

161 regional differences in China's urban-rural income gap and will also

162 provide more detailed data support for subsequent research.

163

The rest of this article is arranged as follows: The second part is

164 literature review; the third part is model setting and data explanation; the

165 fourth part is empirical regression and results in analysis; the fifth part is

166 the impact mechanism test; the sixth part is the relationship between

167 urban-rural income gap and environmental pollution introduced by spatial

168 correlation; the seventh part is a further discussion of the urban-rural

169 income gap and environmental pollution: the perspective of environmental

170 regulation effects; the eighth part is the conclusion and policy 
171 enlightenment.

\section{Literature review}

Grossman and Krueger (1991) and Panayotou (1993) Per capita

175 income and environmental pollution have an "inverted U-shaped" impact,

176 and although the EKC theory has certain flaws, environmental pollution

177 has been incorporated into the income distribution research framework

178 earlier. This is a great enrichment to the theoretical system of the income

179 distribution. In subsequent studies, some scholars believe that the

180 income gap, especially the widening of the urban-rural income gap, will

181 often aggravate environmental pollution. Boyce (1994) established a

182 power-weighted social decision-making model (PSDM) and pointed out

183 that the poor tend to increase the development of natural resources to

184 maintain basic survival, while the rich prefer to transfer assets to other

185 regions when facing environmental pollution instead of investing locally

186 to improve environmental quality, so the widening gap between the rich

187 and the poor will significantly worsen the local environment. From the

188 perspective of public expenditure, Magnani (2000) pointed out that the

189 widening income gap will restrain the government's willingness to spend 
190

191

192

193

194

195

196

197

198

199

200

201

202

203 scholars have pointed out that the urban-rural income gap and

204 environmental pollution may have a non-linear interactive relationship.

205 Lu Li and Gao Hongying (2016) passed the empirical test of the inter-

206 provincial panel secretary and pointed out that China's urban-rural

207 income gap has a significant "inverted U-shaped impact" on regional

208 carbon emissions. Liu et al. (2018) combined the income gap between

209 urban and rural areas in China from 1996 to 2015, carbon emissions, and 
210 the per capita income gap in cities at the prefecture level and above.

211 They empirically support the views of Lu Li and Gao Hongying and point

212 out that per capita income level determines the local EKC inflection

213 point. It can be found that the academic circles still have disputes over

214 the actual impact of the urban-rural income gap on environmental

215 pollution.

In addition, environmental pollution is affected by many factors, and

217 there is a lack of a unified understanding of how the urban-rural income

218 gap through the mechanism path affects environmental pollution. Given

219 the premise of other factors, environmental pollution is mainly closely

220 related to market demand and manufacturer's supply. Because existing

221 research usually only has a single perspective of "market demand" or

222 "manufacturer supply", its research conclusions have obvious blind spots

223 in explaining the dynamic law of China's environmental pollution

224 evolution under the background of the continuous deepening of today's

225 market economic system. Therefore, based on the dual perspectives of

226 "demand-side" and "supply-side", this article summarizes and

227 summarizes the two major mechanism paths through which the urban-

228 rural income gap affects environmental pollution from the theoretical

229 level: 


\subsection{Scale of demand}

232

In the research on the consumer side, all the conclusions are that the

233 scale of demand has an important impact on environmental pollution, but

234 the magnitude and direction of its impact are widely disputed. Some

235 scholars believe that the widening income gap between urban and rural

236 areas has aggravated environmental pollution. Through the 1986-2008

237 China time-series study, Pan Dan and Ying Ruiyao (2010) found that the

238 widening income gap has significantly increased environmental

239 pollution, and the impact has a significant lag. Han Jiabin and Han

240 Mengying (2015) found that the widening income gap will not be

241 conducive to the improvement of the environmental quality of the

242 country after analyzing the experience of translational research. Zhan

243 Hua (2018) believes that the widening of the urban-rural income gap not

244 only reduces the low-income group's consumption preference for

245 environmentally clean products, but may also stimulate the conspicuous

246 consumption of high-income groups, and ultimately lead to the

247 deterioration of the regional environment. The research of Yang Yuhan

248 (2019) also found that the widening of the urban-rural income gap has

249 increased regional environmental pollution by affecting the purchasing 
power of residents.

However, some studies believe that the appropriate expansion of the

252 urban-rural income gap has alleviated environmental pollution. On the

253 one hand, in the initial stage of economic development, an appropriate

254 expansion of the income gap may be beneficial to fostering market

255 demand for environmentally clean products, which in turn has formed the

256 formation of frontier manufacturers to maintain production. It is

257 beneficial to curb regional environmental pollution (Foellmi,

258 Zweimüller, 2006; Li Pingping, 2012). Liu Donghuang and Shen

259 Kunrong (2012) found through empirical research that the narrowing of

260 the urban-rural income gap will increase the overall consumption scale

261 of the market, while Zhu Qin et al. (2012) calculated by using a sequence

262 table of comparable input-outputs and found that the expansion of the

263 consumption scale of Chinese residents will aggravate the environment

264 Pollution. Ma Xiaowei et al. (2019) also found through empirical tests

265 that the widening of the urban-rural income gap in China's provinces and

266 municipalities from 2000 to 2012 significantly suppressed consumer

267 carbon emissions. 


\subsection{Human capital}

270

271 effectively improve local environmental pollution has become a basic

272

273 still some controversy about how the urban-rural income gap affects

274 regional labor costs. Many opinions believe that the widening of the

275 urban-rural income gap will inhibit the accumulation of human capital.

276 Chao Xiaojing and Shen Kunrong (2014), from the perspective of China's

277 inter-provincial level, found that the expansion of the urban-rural income

278 gap in provincial administrative regions from 1995 to 2012 will

279 strengthen rural residents' education investment financing constraints,

280 which will not be conducive to the accumulation of human capital in the

281 region. Lv Wei et al. (2015) also believe that the widening of the urban-

282 rural income gap will lead to educational inequality, which is not

283 conducive to human capital accumulation in the long run. Based on

284 China's current national conditions, Zhang Laiming and Li Jianwei

285 (2016) pointed out that the expansion of urban and rural income is not

286 conducive to the equalization of labor quality, and the limited investment

287 in the human capital of rural residents will significantly hinder the

288 expansion of human capital in China. 

only significantly increases the productivity of high-skilled labor, but also produces significant positive externalities to other residents (Liang

292 Wenquan and Lu Ming, 2015). The possible reason is that

293 environmentally clean products are technology-intensive products, and 294 their R\&D and production may require key breakthroughs by top talents 295 at certain stages. The moderately widening urban-rural income gap leads 296 to the differentiation of human capital and may have a positive effect on 297 the cultivation of top talents (Zweimuller, 2000). In other words, in the 298 period when the overall human capital is insufficient, the expansion of 299 urban and rural income can promote the accumulation and agglomeration 300 of high-skilled human capital in certain periods and is conducive to the 301 production of technology-intensive products including environmentally 302 clean products. Gao Fan and Wang Yanan (2016) also believe that the 303 structural agglomeration of human capital caused by the expansion of the 304 urban-rural income gap may promote innovation. Sun Haibo et al. (2017) 305 found that the accumulation of human capital reaches a certain threshold 306 before it can play a significant upgrade and innovation effect. Therefore, 307 it can be found that in some cases, although the expansion of the urban308 rural income gap has led to a slowdown in the accumulation of human 
309

310

capital, the innovative effect of the spatial accumulation of high human capital may help alleviate regional environmental pollution.

Based on the above-mentioned theoretical induction and logical deduction, as well as current China's actual national conditions, this article puts forward the following hypotheses:

$$
\text { Hypothesis 1: The urban-rural income gap significantly affects }
$$

China's environmental pollution, and the impact may exhibit EKC-type nonlinear characteristics.

China has a vast territory, and many conditions such as historical development, geographical location, factor endowments, institutional policies, etc., have significant differences between regions, which also makes China's economic development also show obvious differences. Based on the consumption scale theories such as Zhan Hua (2016), Li Zihao (2017), and Liu (2018) and the human capital theories sorted out in the previous article, this article further proposes:

24 Hypothesis 2: The impact of the urban-rural income gap on environmental pollution has not only the threshold effect of consumption scale but also the threshold effect of human capital. This phenomenon also has a significant geographic location. 


\subsection{Model assumptions}

following empirical model based on existing research:

$$
P I_{i t}=\beta_{0}+\beta_{1} G_{i t}+\beta_{2}\left(G_{i t}\right)^{2}+\lambda D+\xi_{i t}
$$

341 income gap on China's environmental pollution, this paper introduces the

342 quadratic term of the urban-rural income gap to investigate its possible nonlinear impact on environmental pollution.

\subsection{Variable selection and description}


347 level to use the carbon emissions of the above-mentioned cities as a

348 measure of regional environmental pollution. The main reasons are: first

349 of all, with the emergence of events such as "global warming and sea-level

350 rise", "the bleak future of the "Kyoto Protocol", "the escalation of disputes

351 in the Paris Climate Agreement" and other events in recent years, countries

352 and regions have become more concerned about the issue of carbon

353 emissions. Secondly, China has grown into a newly industrialized country

354 in the world, and carbon emissions, as an important indicator of the degree

355 of industrialization, are closely related to industrial growth and

356 transformation and upgrading; Finally, compared to factors such as sulfur

357 dioxide emissions, wastewater emissions, smoke and dust emissions,

358 China's carbon emissions related data are more complete and more credible.

359 Therefore, in the empirical stage, this article chooses carbon emissions as

360 a measure of urban pollution.

(1)Total regional carbon emissions $(\mathrm{CO} 2)$. This article studies the environmental pollution of production and life in prefecture-level and

363 above areas. Since the carbon emissions of industrial power generation 364 mainly come from thermal power generation, and China's factor 365 endowment has long been "rich in coal and poor in oil", which has led to 
366 a high degree of dependence on coal for domestic power production.

367 Therefore, this article refers to the method of Han Feng and Xie Rui (2017),

368 Selecting the carbon emissions of coal, natural gas, and liquefied

369 petroleum gas consumption in the region to estimate the carbon emissions

370 of the entire region. The specific estimation methods are as follows:

$$
I_{i, t}=C_{\text {coal }, i, t}+C_{\text {natural }, i, t}+C_{\text {liquid }, i, t}=\sigma \times \omega \times E_{\text {coal }, i, t}+\theta \times E_{\text {natural }, i, t}+\mu \times E_{\text {liquid }, i, t}
$$

Among them, I represent the total carbon emissions of cities at the

374 prefecture level and above. $\mathrm{C}_{\text {coal }}, \mathrm{C}_{\text {natural }}$, and $\mathrm{C}_{\text {liquid }}$ are the carbon

375 emissions of coal, natural gas, and LPG respectively; Eelectricity, Enatural,

376 and $E_{\text {liquid }}$ are the regional power generation, natural gas power generation,

377 and LPG power generation, respectively; $\sigma$ is the carbon dioxide emissions

378 coefficient of coal, the equivalent value is $1.3023 \mathrm{~kg} / \mathrm{kWh}$ (Ma Zhonghai

379 et al., 1999); $\omega$ is the proportion of coal power generation in the total 380 power generation. Because coal power generation statistics are gradually 381 released after 2012, and coal power generation has long been the total 382 thermal power generation in China, this paper selects thermal power 383 generation as a substitute variable for coal power generation for 384 conversion; $\theta$ is the carbon dioxide emission coefficient of natural gas, 
385 and $\mu$ is the carbon dioxide emission coefficient of liquefied petroleum 386 gas.

(2) This article uses per capita carbon emissions (total carbon 388 emissions/GDP, PI_P, kg/person) to reflect the carbon emissions of cities 389 at prefecture-level and above in China, and adopts carbon emission 390 intensity (total carbon emissions/GDP, PI_G, kg/yuan) )as a substitute 391 variable for robustness discussion. measurement method of the Gini coefficient in Chen Gang's (2011) research, this paper intends to adopt the urban Gini index (Gini Index) to 396 reflect the regional urban-rural income gap. The specific calculation 397 formula is:

$$
G_{i t}=1-p_{i r t} \bullet w_{i r t}+p_{i u t} \bullet\left(2-w_{i u t}\right)
$$
400 population and urban population at prefecture level and above; $\mathrm{w}_{\mathrm{r}}$ and $\mathrm{w}_{\mathrm{u}}$ 401 are the proportions of rural population's total income in the total regional 402 income, and the proportion of urban population's total income in the total 403 regional income. The value range of the urban-rural Gini coefficient is 
$404[0,1]$. The larger the value, the larger the urban-rural income gap, and vice 405 versa, the smaller. Since China's urban population data of prefecture-level 406 and above cities have been published relatively and completely in various 407 statistical yearbooks and statistical bulletins since 2005 , and the relevant 408 data has been seriously missing again after 2015, the period of this paper 409 is 2005-2015, and the urban-rural Gini coefficient of 270 cities at 410 prefecture-level and above in China from 2005 to 2015 was calculated 411 based on the above method.

\subsubsection{Control variables}

(1) Industrial structure (structure). Ma and Stern (2008) believe that

414 the upgrading of the industrial structure reduces regional carbon emissions, 415 and Shao Shuai et al. (2019) also pointed out that the upgrading of the 416 industrial structure will increase the level of local carbon emissions. This 417 article refers to the research of Yuan Yuan et al. (2016) and uses the 418 logarithm of the per capita added value of the secondary industry $(10,000$ 419 yuan/person).

(2) Economic openness (FDI). Given the serious lack of urban trade

421 data within the research span, this article intends to use the foreign

422 direct investment to reflect the degree of regional economic openness. 
423 Xu Helian and Deng Yuping (2012) found that technological

424 improvements brought about by foreign direct investment have

425 significantly improved China's environmental pollution; however, the

426 "pollution paradise" hypothesis argues that foreign direct investment

427 often brings environmental pollution to the host country's low-end

428 industries (Markusen And Venables, 1999; Keller and Levinson, 2002).

429 And this article selects the logarithm of the local per capita foreign

430 direct investment (USD/person) as an indicator reflecting the degree of

431 capital freedom.

(3) Degree of urbanization (urban). Zhang Tengfei et al. (2016)

433 pointed out that the expansion of urbanization has increased local carbon

434 emissions, and Liddle (2004) also believes that urbanization may help

435 alleviate carbon emissions. Therefore, this paper selects the proportion of

436 the urban population in the total population to reflect the degree of

437 urbanization in the region.

(4) Infrastructure. He Wenju(2019) found that improved

439 infrastructure will increase residents' public transportation utilization rate

440 and reduce carbon emissions. Indicators such as highway mileage and

441 railway mileage within the jurisdiction can reflect the level of regional

442 infrastructure construction to a certain extent. This paper selects the 
443 number of buses per capita (vehicles/10,000 people) in cities at and above

444 the local level to measure the level of regional infrastructure.

445

(5) Finance. Lu Hongyou et al.(2015) believe that the current fiscal

446 expansion has regulated regional pollution to a certain extent. However,

447 Feng Haibo and Fang Yuanzi (2014) found that the negative effects of the

448 expansion of public fiscal expenditures on China's environmental

449 pollution control have gradually emerged. This paper selects the

450 proportion of local annual fiscal expenditures in GDP and takes the

451 logarithm to measure the intensity of local public fiscal expenditures.

452

(6) Leverage. Tamazian et al.(2009) found that financial development

453 has a significant inhibitory effect on per capita carbon emissions, but

454 Boutabba (2014) believes that financial expansion has increased the total

455 regional carbon emissions. Therefore, this article selects the regional

456 financial leverage ratio as a measure of the degree of regional financial

457 development. The specific calculation method is: leverage ratio= the

458 balance of various loans of financial institutions at the end of the year/GDP.

\subsection{Data sources and statistical analysis of variables}

The period of the sample data in this article is selected from 2005 to

461 2015. The selected relevant data mainly come from the "China Statistical 
462 Yearbook", "China City Statistical Yearbook", "China Regional Statistical

463 Yearbook", "China Electric PowerYearbook", statistical yearbooks of

464 various provinces and cities, and annual statistical bulletins of cities at

465 the prefecture-level and above. To avoid the heteroscedasticity problem

466 that may appear in the empirical process, this paper has carried out

467 logarithmic processing on some variables. In particular, this article is

468 restricted by the statistical results of urban and rural permanent residents

469 in various yearbooks and statistical bulletins and excludes the urban and

470 rural Gini coefficients of all cities in Jilin Province. In addition, to obtain

471 balanced panel data, this paper further excluded some data from

472 prefecture-level and above cities with a serious lack of relevant data. The

473 statistical description of the variables is shown in Table 1:

Insert Table 1

475

\section{Empirical Results and analysis}


481 basic model. Model 1 examines the relationship between the urban and

482 rural Gini coefficient and per capita carbon emissions without the control

483 variables. Model 2 adds control variables but does not control the regional

484 and time effects. Model 3 further controls the regional and time effects.

485 The results show that the primary parameter of the urban-rural Gini

486 coefficient is significantly positive, and the quadratic parameter is

487 significantly negative, indicating that the impact of the urban-rural income

488 gap on urban pollution in the process of expanding is "inverted U-shaped",

489 which is consistent with the previous hypothesis; After the effects of

490 control variables and control areas and time, the significance of the

491 primary and secondary terms of the urban and rural Gini coefficients in

492 Model 3 and the parameter values did not change significantly compared

493 with Models 1 and 2, indicating that the selection of control variables is

494 reasonable and the model is designed. According to the primary and

495 secondary parameter values of the urban-rural Gini coefficient, it can be

496 found that the inflection point of the urban-rural income gap on urban

497 pollution is at 0.2779 , that is, when the urban-rural income gap is lower

498 than 0.2779 , the expansion of the urban-rural income gap increases the

499 area per capita and when carbon emissions are higher than 0.2779 , the

500 urban-rural income gap widens and reduces per capita carbon emissions. 
502 rate in each of the control variables of Model 3 are significantly positive,

503 indicating that an increase in the proportion of the secondary industry's

504 added value in GDP will increase per capita carbon emissions. In other

505 words, the current economic growth model characterized by the expansion

506 of the secondary industry has significantly increased regional

507 environmental pollution. The parameter of FDI is significantly negative,

508 which shows that in China, FDI has significantly improved China's

509 environmental pollution through the technology diffusion effect, while its

510 "pollution paradise" effect is relatively limited in China. The parameter of

511 the urbanization rate is significantly positive, indicating that China's rapid

512 industrialization and urbanization have aggravated environmental

513 pollution for a long time. Infrastructure parameters are not significant,

514 indicating that it has no significant relationship with the environmental

515 pollution in China. The coefficient of fiscal expenditure is significantly

516 negative, indicating that an increase in government expenditure will

517 increase per capita carbon emissions. The leverage ratio parameter is

518 significantly negative, indicating that regional financial development may

519 help to weaken production financing constraints, encourage corporate

520 research and development, and upgrade to alleviate local pollution. In 
521 terms of the symbol and significance of comprehensive control variables,

522 industrial structure, FDI, urbanization rate, fiscal expenditure, and

523 leverage ratio will significantly affect local environmental pollution.

524 Therefore, the current energy-saving and emission-reduction targets can

525 mainly focus on optimizing industrial structure, economic opening,

526 urbanization, government finance, and regional financial development.

Model 3 is the empirical result of the fixed effects panel model (IV-

528 FE) under the condition that the explained variable lags one period as the

529 instrumental variable. The result shows that the primary and secondary

530 parameters of the urban and rural Gini coefficient are significant, and the

531 signs are consistent with expectations. Model 4 shows the influence of the

532 urban and rural Gini coefficient on the per capita carbon emission intensity

533 under the PCSE model. The first term of the urban and rural Gini

534 coefficient is significantly positive and the second term is significantly

535 negative, which is also consistent with the original model. Therefore, in

536 combination with the models $1-5$ in Table 2 , it can be found that the urban-

537 rural income gap in prefecture-level and above cities in China from 2005

538 to 2015 has a significant "inverted U"-shaped impact on urban pollution. 
543 bilateral tailing of $1 \%$ on the explained variables respectively. Among

544 them, the primary parameter of the urban and rural Gini coefficient was

545 significantly positive, and the quadratic parameter was significantly

546 negative, which was consistent with the regression results of the basic

547 model; The inflection points of Model 1-2 are 0.2727 and 0.2953, which

548 are still close to the results of the basic model. Model 3 uses carbon

549 emission intensity to replace the original indicator as to the explained

550 variance of the model. The primary term of the urban and rural Gini

551 coefficient is significantly positive, and the second term is significantly

552 negative. The inflection point is about 0.3070 , which is also basically

553 consistent with the original model. Model 4 replaces the original control

554 variables with the one-period lagging term of the control variables to

555 conduct an empirical test on the original model. The urban-rural Gini

556 coefficient is still significantly positive for the primary term and

557 significantly negative for the quadratic term, and the inflection point is at

558 about 0.2546 which is still consistent with the original model. 
(2) Endogenous testing. Given the serious endogeneity between the

560 variables may have a significant impact on the empirical regression results,

561 this article must fully consider the potential endogeneity of the model. On

562 the one hand, the setting of the empirical model in this paper cannot

563 include all the factors that affect environmental pollution, such as

564 environmental protection expenditures and R\&D personnel in cities at and

565 above the level; on the other hand, there is a two-way cause and effect

566 between the explained variables and explanatory variables of the empirical

567 model in this paper. The relationship is that the urban-rural income gap

568 affects environmental pollution, and environmental pollution, in turn,

569 affects the urban-rural income gap. Therefore, this article refers to the

570 research of Gao Fan and Wang Yanan (2016) and selects the explanatory

571 variable to lag one period as an instrumental variable to test the model's

572 endogeneity. The results are shown in Model 5, the Hansen test value is

573 within a reasonable interval, indicating that the selection of the

574 instrumental variables in this paper is reasonable and effective; after the

575 system GMM model is used to deal with the endogenous problem, the

576 primary parameter of the urban and rural Gini coefficient is significantly

577 positive, and the quadratic parameter is significant It is negative, which is

578 consistent with the empirical results of the basic model; in Model 5, the 
579 inflection point of the urban-rural income gap on China's environmental

580 pollution is located at about 0.2615 , which is not much different from the

581 inflection point of the basic model.

582

Therefore, combining the two-sided shrinking test, the two-sided

583 censoring test, the explanatory variable/explanatory variable index

584 replacement method, and the systematic GMM method can be considered

585 that the empirical results of the basic model are robust.

586

Insert Table 3

587

588

\subsection{Heterogeneity analysis}

589

Given China's vast territory, factors such as geographic location,

590 factor endowments, and historical conditions have significant

591 heterogeneity among regions, and the above heterogeneity may lead to

592 differences in the impact of the urban-rural income gap on urban

593 environmental pollution. Therefore, it is very important to discuss the

594 heterogeneity of urban environmental pollution caused by the urban-rural

595 income gap. This article refers to existing research and uses three

596 classification standards to discuss consistency: First, according to the

597 practice of most traditional documents, the sample cities are divided into 
598 eastern, central, and western regions according to their geographic 599 location; the second is to draw on the research of Li Jingrui (2017), divide 600 the median of the sample capital-labor ratio in 2013 as the dividing line, 601 and divide the cities into high and low according to the capital-labor ratio 602 of each city in 2013; the third is to refer to the method of city size division 603 by Sun Weizeng et al. (2018) and classify cities with an urban population 604 of more than 3 million in 2013 as large cities, and classify them as small 605 and medium-sized cities with an urban population of less than 3 million. 606 The results of heterogeneity analysis are shown in Table 4:

608 urban-rural income gap on urban pollution in the eastern, central, and 609 western regions of China. Among them, the "inverted U-shaped" impact of 610 the urban and rural Gini coefficient on per capita carbon emissions is more 611 significant in the eastern, central, and western regions of China. From the 612 perspective of the inflection point of environmental pollution, the 613 inflection points in the eastern, central, and western regions are 0.2276, 6140.2574 , and 0.2860 respectively, which are all within the value range of $615[0,1]$, indicating that the income gap between urban and rural areas in 616 China from 2005 to 2015 has a significant "inverted U-shaped" impact on 617 environmental pollution in the eastern, central, and western regions. In 
618 addition, the inflection point of China's environmental pollution has been

619 increasing from the east, middle, and west, indicating that from the east

620 to the west, the pollution incentive range of the widening urban-rural

621 income gap in China has shown a continuous expansion. Among the control

622 variables, industrial structure, urbanization, and fiscal intensity have

623 significantly expanded environmental pollution in the eastern region,

624 while FDI and infrastructure have significantly suppressed environmental

625 pollution, and the environmental pollution effect of the leverage ratio is

626 not significant; for the central region, the urbanization rate, fiscal

627 intensity, and increased environmental pollution have no significant

628 impacts on other factors; for the western region, the industrial structure

629 and urbanization rate are the main factors affecting local environmental

630 pollution, and the effects of other factors are less obvious.

631 Model 4-5 gives the empirical results of capital-labor endowment 632 heterogeneity. The first-order parameter of the urban-rural Gini coefficient

633 in areas with a high capital-labor ratio and the low-capital-labor ratio is

634 significantly positive, and the quadratic parameter is significantly

635 negative. Moreover, the environmental inflection point of areas with a

636 high capital-labor ratio is located at 0.2797 , while the environmental

637 inflection point of areas with a low capital-labor ratio is located at 0.2784 . 
638 The inflection points of the two types of areas are similar. Therefore, the 639 income gap between urban and rural areas in China is either in areas with 640 high capital-labor ratios or areas with high capital-labor ratios. Areas with 641 low capital-labor ratios all have a significant "increase" and then 642 "decrease" influence on environmental pollution, and there is no 643 significant difference in the locations of the environmental pollution peak 644 points of the urban-rural income gap between the two types of areas. 645 Among the control variables, the industrial structure of cities with high 646 capital-labor ratio, urbanization rate, and fiscal strength are the main 647 factors that increase environmental pollution, while FDI plays a major role 648 in reducing pollution; for cities with low capital-labor ratios, the industrial 649 structure and urbanization rate are the main factors that exacerbate urban 650 pollution, while FDI and leverage have significantly suppressed local 651 pollution.

652 In addition, this article draws on the research of Sun Weizeng et al. 653 (2018), classifies cities at prefecture level and above with urban 654 populations of more than 3 million in 2015 as large cities, and classifies 655 the remaining samples as small and medium-sized cities, trying to discuss 656 the heterogeneous impact of urban-rural income gap on environmental 657 pollution from the perspective of city scale, and the results are shown in 
658 Model 6-7. The results show that the urban-rural Gini coefficient of large

659 cities and per capita carbon emissions show a "rising first and then 660 suppressing", with an inflection point at 0.2039 ; while the urban-rural 661 Gini coefficient of small and medium-sized cities also shows a trend of 662 "rising first and then suppressing" per capita carbon emissions, its 663 inflection point is at 0.2903 , which is much larger than that of large cities.

664 Therefore, the urban-rural income gap between the two cities has the same 665 impact on environmental pollution. The scope of pollution incentives for 666 the income gap between urban and rural areas is much higher than that in 667 large cities. Among the control variables, the industrial structure, 668 urbanization rate, and fiscal intensity in large cities have increased 669 environmental pollution, while FDI and infrastructure have played a good 670 environmental cleaning effect; for small and medium-sized cities, the 671 industrial structure and urbanization rate have increased environmental 672 pollution. The main factors of pollution and FDI and leverage ratio have a 673 significant positive effect on reducing local pollution.

674 In summary, the "inverted U-shaped" impact of the urban-rural income 675 gap on environmental pollution is significant in the eastern and central 676 regions, but not in the western region. In addition, the environmental 677 inflection point of the urban-rural Gini coefficient in the central region, 
678 high-capital-labor regions, and small and medium-sized cities is far away.

679 Therefore, the urban-rural income gap has only an increased effect on

680 regional environmental pollution in reality; while the environmental

681 inflection points of the eastern region, low-capital labor regions, and

682 urban-rural Gini coefficients of large cities are located at a lower position.

683 Therefore, the urban-rural income gap in the above-mentioned regions has

684 a significant "inverted U-shaped" impact on environmental pollution.

685

Insert Table 4

686

687

\section{Mechanism test}

688

The previous article empirically tested the actual impact of China's

689 urban-rural income gap on environmental pollution and discussed its

690 robustness and heterogeneity. As mentioned above, the urban-rural income

691 gap has an impact on the regional environment from both the demand and

692 supply sides. Therefore, from the demand side, this article uses the

693 logarithm of the regional per capita consumption (yuan/person) as an

694 intermediary index to test the changes in the urban-rural income gap. The

695 actual impact of changes in the scale of demand, which in turn leads to

696 changes in regional environmental pollution, is specifically measured as 
697 follows:

$$
\text { consumption }_{i t}=\text { consumption }_{\text {iut }} \bullet p_{\text {iut }}+\text { consumption }_{\text {irt }} \bullet p_{\text {irt }}
$$
Among them, consumption ${ }_{i t}$ represents the actual per capita actual 700 consumption expenditure of cities at the I prefecture level and above in 701 year t (thousand yuan/person), consumption ${ }_{i u t}$ and consumption ${ }_{\text {irt }}$ are the 702 actual urban per capita consumption expenditures and rural per capita 703 actual consumption expenditures, respectively. Among them, 704 consumption $_{\text {iut }}$ and consumption irt $_{\text {are }}$ the per capita nominal consumption 705 expenditure of urban residents and the per capita nominal consumption 706 expenditure of rural residents, respectively, obtained by deflation 707 according to the urban consumer price index of the province (city) where 708 the city is located and above, and the consumer price index of rural 709 residents in China (base period: 2005). In addition, this article uses the 710 human capital index as an intermediary indicator to test from the 711 perspective of the supply side that the urban-rural income gap causes 712 changes in human capital, and then affects the actual impact of 713 environmental pollution. The calculation method of the human capital 714 index is as follows:

$$
h_{i t}=\frac{e d u_{i p t} \bullet 6+e d u_{i j t} \bullet 12+e d u_{i c t} \bullet 16}{d u_{i p t}+e d u_{i j t}+e d u_{i c t}}
$$



school, and university, respectively. the empirical model as:

$$
P I_{i t}=\alpha_{40}+\alpha_{41} G_{i t}+\alpha_{43} H C_{i t}+\alpha_{44} G_{i t} \bullet H C_{i t}+\lambda D+\varepsilon_{i t}
$$
urban-rural income gap. Equations 3-4 test the mediating effects of per capita consumption and human capital in the process of urban-rural income 
734 terms of the urban-rural income gap and per capita consumption, and 735 human capital index to the original model, and comprehensively examines

736 the changes in market demand and human capital caused by changes in 737 urban-rural income gap, and thus the actual impact on urban pollution. The 738 test results are shown in Table 5 below:

742 income gap in cities at the prefecture-level and above in China from 2005 to 2015 has generally restrained regional consumption and human capital.

744 And through the test results of Model 3, it can be found that the expansion 745 of the consumption scale can not only increase the consumption of 746 environmentally friendly products and reduce pollution, but also may 747 increase environmental pollution due to the restriction of the urban-rural 748 income gap. The results of Model 4 show that although the accumulation 749 of human capital helps directly reduce urban environmental pollution, the 750 urban-rural income gap can also increase environmental pollution through 751 the indirect effects of human capital. 
753 capita consumption, human capital, and their respective interactions with

754 urban and rural Gini coefficients into the model, at the end of the demand

755 scale, the parameter of per capita consumption is significantly negative,

756 and the parameter of the interaction term with the urban-rural income gap

757 is significantly positive, which means that the expansion of demand

758 directly reduces urban pollution on the one hand. This may be caused by

759 the upgrade of demand caused by consumption expansion and then promote

760 the consumption of environmentally friendly products; on the other hand,

761 the urban-rural income gap may indirectly and significantly restrain the

762 overall consumption scale of environmentally friendly products through

763 the income distribution effect while the scale of demand is expending. On

764 the human capital side, the human capital index parameter is significantly

765 negative, and the interaction term with the urban-rural income gap is

766 positive. This shows that the expansion of human capital also directly

767 reduces urban pollution. This is obviously because the expansion of human

768 capital has expanded the accumulation of skilled labor. "Pool" actively

769 promotes the production of environmentally friendly products by

770 enterprises; however, the urban-rural income gap induces the formation of

771 a small amount of high-end human capital through the income distribution

772 effect, and indirectly hinders the improvement of the regional environment 
773 by inhibiting the accumulation of local human capital. The test results of

774 Model 5 are further obtained after the first derivative of the demand scale

775 and human capital are obtained:

776

$$
\frac{\partial P I}{\partial \text { consumption }}=1.6854 G-0.2203, \frac{\partial P I}{\partial H C}=6.9450 G-2.1161
$$

When $\partial P I / \partial$ consumption $=0$ it can be found that the environmental

778 pollution inflection point of the urban and rural Gini coefficient to per

779 capita consumption is at 0.1307 , that is, when the urban and rural Gini

780 coefficient is less than 0.1307 , the expansion of per capita consumption

781 alleviates environmental pollution; when the urban and rural Gini

782 coefficient is greater than 0.1307 , the expansion of per capita consumption

783 aggravates environmental pollution. And when $\partial P I / \partial H C=0$ it was found

784 that the environmental pollution inflection point of the urban-rural Gini

785 coefficient on the human capital index was at 0.3047 , that is, when the

786 urban-rural Gini coefficient was less than 0.3047 , the human capital index

787 had a depressing effect on per capita carbon emissions; when the urban-

788 rural Gini coefficient was greater than 0.3047 , the human capital index

789 promotes per capita carbon emissions.

Based on the above results, it can be concluded that the scale of

791 demand and human capital have significantly affected environmental 
792 pollution and the impact has a "positive U-shaped" trend, and the urban793 rural income gap has played a key control role in the above-mentioned 794 impact process.

795 environmental pollution introduced by spatial correlation

With the strengthening of China's regional integration trend, the correlation between production and consumption in various regions continues to deepen. Given the possible spatial correlation of environmental pollution, the concept of "spatial correlation" needs to be 803 introduced when examining the environmental pollution effects of the 804 urban-rural income gap. In other words, the environmental pollution 805 among cities above the prefecture-level in China may be geographically related. To characterize the spatial correlation of environmental pollution

807 between regions, it is required to select an appropriate spatial weight 808 matrix to modify the original model. This article uses Moran's I index to 809 reflect the relevance of regional environmental pollution, and its basic expression is as follows: 


$$
\text { Moran' } s_{-} I=\frac{\sum_{i=1}^{n} \sum_{j=1}^{n} d_{i j}\left(P I_{i}-\overline{P I}\right)\left(P I_{j}-\overline{P I}\right)}{S^{2} \sum_{i=1}^{n} \sum_{j=1}^{n} d_{i j}}
$$

813 of cities at the prefecture-level and above (the value is 270 in this paper),

814 and $d_{i j}$ is the spatial weight matrix. Considering that the spatial correlation

815 of environmental pollution is mainly manifested in the degree of

816 geographical distance, this paper selects the geographical distance matrix

817 as the space weight matrix, and the geographical distance matrix is defined

818 as $d_{i j}=\left\{\begin{array}{l}1 / d^{2}, i \neq j \\ 0, i=j\end{array}\right\} \mathrm{d}$ is the distance between the urban areas of two

819 prefecture-level and above cities.

820 Concerning existing research, this paper sets the environmental

821 pollution model of the urban-rural income gap including spatial

822 correlation as:

$$
P I_{i t}=\alpha_{60}+\alpha_{61} G_{i t}+\alpha_{62}+\left(G_{i t}\right)^{2} \lambda D+\rho+\varepsilon_{i t}
$$


827 the spatial correlation, the primary parameters of the urban and rural Gini

828 coefficients in the full sample and the eastern, central, and western

829 samples are still significantly positive, and the quadratic parameters are

830 significantly negative, and the size and sign of the parameter are similar

831 to the regression results of the basic model, indicating that from 2005 to

8322015 , the impact of urban-rural income gaps on environmental pollution

833 in all prefecture-level and above cities in China or eastern, central, and

834 western cities showed a steady "inverted U-shaped" trend. The

835 environmental inflection points of the country, the east, the central, and

836 the west are located at $0.2510,0.2205,0.2505$, and 0.2672 respectively,

837 which have not changed much from the basic model. In addition, the sign,

838 size, and significance of the control variables are not much different from

839 the regression results of the basic model. Therefore, it can be considered

840 that it is reasonable to incorporate spatial correlation into the basic model.

841 In addition, after incorporating spatial correlation into the basic model,

842 the $\rho$ parameter is positive across the country and in the eastern, central,

843 and western regions, and both have passed the $1 \%$ significance test,

844 indicating that whether it is in the country or the eastern, central, and

845 western regions internally, there is a significant positive spatial

846 correlation between environmental pollution in cities at prefecture level 
847 and above. In other words, the increase in the environmental pollution in 848 a specific area will significantly drive environmental pollution in 849 surrounding areas. effects

855

857 has a significant "inverted U-shaped" impact on urban pollution, and this

858 impact is realized through its nonlinear impact on the scale of demand

859 and human capital. So in the context of China's increasingly strict

860 environmental system in recent years, what is the actual impact of the

861 urban-rural income gap on urban pollution? Based on the above

862 perspective, examining the actual impact of urban-rural income disparity

863 on urban pollution may help to better understand the inherent

864 relationship between China's urban-rural income disparity and regional

865 environmental pollution. Zhanhua (2018) pointed out that the intensity of 
866 environmental regulations and the urban-rural income gap has had a

867 significant impact on the regional environment. Therefore, this paper re-

868 examines the urban-rural income gap and environmental pollution in

869 cities at the prefecture level and above in China from the perspective of

870 the intensity of environmental regulations.

871 Environmental regulation intensity (regulation). Existing studies

872 have adopted three main types of environmental regulation indicators:

873 one is the proportion of pollution investment and pollution charges in

874 each region in the added value of the secondary industry; the other is the

875 laws, regulations, policies, rules, and regulations related to the

876 environment formulated and promulgated for the region organizing

877 documents, using the number of results to reflect the intensity of

878 regional environmental regulations; third, constructing the intensity of

879 local pollution emissions and the intensity of environmental regulations

880 with the help of regional industrial smoke, industrial wastewater, and

881 sulfur dioxide emissions as a proportion of the added value of the

882 secondary industry. As this article selects China's prefecture-level and

883 above cities from 2005 to 2015 as the research object, this article refers

884 to the research of Song Deyong and Yang Qiuyue (2019) and uses

885 industrial smoke, industrial wastewater, and sulfur dioxide emissions to 
886 account for the proportion of the secondary industry's added value in

887 2005-2015 China's prefecture-level and above cities' environmental

888 regulation intensity index, the specific calculation method is as follows:

$$
p d_{i j t}=p_{i j t} / G D P_{\mathrm{sec}, i j t}
$$

891 pollutant from prefecture-level and above cities in year t, GDP ${ }_{\text {sec }}$

892 represents the added value of the secondary industry, and pd represents

893 the pollution emission intensity per unit of the added value of the

894 secondary industry. On this basis, the above calculation results are

895 further standardized:

896

$$
p d_{i j t}^{s}=\frac{p d_{i j t}-\min p d_{j}}{\max p d_{j}-\min p d_{j}}
$$

898 the above results, the intensity of environmental regulations can be

899 calculated:

900

$$
\text { regulation }_{i t}=\frac{n}{\sum_{j=1}^{n} p d_{i j t}^{s}}
$$

901 To investigate how the urban-rural income gap affects urban

902 pollution from the perspective of environmental regulation, this paper 
903 introduces environmental policies based on the original model, to

904 explore the actual effect of environmental regulation in the impact of the 905 urban-rural income gap on environmental pollution, the model is as 906 follows :

$$
\begin{gathered}
G_{i t}=\beta_{10}+\beta_{11} \ln r e g_{i t}+\lambda D+\varepsilon_{i t} \\
P I_{i t}=\beta_{20}+\beta_{21} G_{i t}+\beta_{22} \ln r e g_{i t}+\lambda D+\varepsilon_{i t} \\
P I_{i t}=\beta_{30}+\beta_{31} G_{i t}+\beta_{32} \ln r e g_{i t}+\beta_{33} \ln r e g_{i t}+\lambda D+\varepsilon_{i t} \\
P I_{i t}=\beta_{40}+\beta_{41} G_{i t}+\beta_{42}\left(G_{i t}\right)^{2}+\beta_{43} \ln r e g_{i t}+\beta_{44} \ln r e g_{i t}\left\lceil G_{i t}+\lambda D+\varepsilon_{i t}\right.
\end{gathered}
$$

913 logarithm of the environmental regulation intensity index, abbreviated as

914 lnreg. The results are shown in Table 7. The results of Model 1 show that

915 the lnreg parameter is significantly negative, indicating that

916 environmental regulations have significantly suppressed the urban-rural

917 income gap. From the results of Model 2, it can be found that the

918 primary parameter of environmental regulation is significantly negative,

919 and the second parameter is significantly positive. This indicates that theoretically, the impact of environmental regulation on environmental

921 pollution is "inhibiting" and then "promoting" positive. The possible 
922 reason for the "U-shaped" trend is that: appropriate environmental

923 regulations can help eliminate high-polluting enterprises and effectively

924 regulate residents' consumption behavior. Industrial transformation and

925 consumption upgrades can effectively reduce environmental pollution;

926 however, as the intensity of regulation continues to increase, the

927 excessive environmental threshold may not only inhibit the daily needs

928 of ordinary residents but also force companies to "steal discharge" of

929 pollutants, which will increase environmental pollution. According to

930 Model 3, it can be seen that the urban and rural Gini coefficient

931 parameter is significantly positive, that is, the expansion of the urban

932 and rural Gini coefficient in China at this stage has increased the local

933 per capita carbon emissions as a whole. Model 4 adds the urban-rural

934 Gini coefficient based on Model 2. As a result, the primary term of

935 environmental regulation is significantly negative, the second term is

936 significantly positive, and the parameter of the urban-rural income gap is

937 significantly negative. Therefore, it can be considered that the urban-

938 rural Gini coefficient has played a significant intermediary role in the

939 process of environmental regulation in the process of "suppressing" and

940 then "promoting" carbon emissions per capita. That is, appropriate

941 environmental regulations can help improve the urban-rural income gap, 
942 and thus reduce environmental pollution, in turn, excessively stringent

943 environmental regulations may increase the income gap between urban

944 and rural areas and worsen the regional environment.

\section{Conclusions and policy implications}

952 urban-rural income gap in China's prefecture-level and above cities on

953 environmental pollution from 2005 to 2015 . Different from the existing

954 research which mainly starts from the perspective of income level, this

955 article first points out from the theoretical and logical level: the urban-

956 rural income gap mainly affects environmental pollution through the

957 scale of demand and human capital, and the above-mentioned mechanism

958 constitutes the impact of the urban-rural income gap an important reason

959 for the "inverted U-shaped" trend effect in which environmental

960 pollution first increases and then decreases. Based on the above logical 
961 deduction, this paper uses panel data from 270 prefecture-level and

962 above cities in China from 2005 to 2015 for empirical testing. The

963 results show that the income gap between China's urban and rural areas

964 has indeed led to an "inverted U-shaped" trend in local environmental

965 pollution, and the inflection point of environmental pollution appears at

966 0.2779. The "inverted U-shaped" trend of environmental pollution of the

967 urban-rural income gap is notable in the eastern, central, and western

968 regions, regions with high capital-labor ratio, low capital-labor ratio, or

969 large and small cities. The urban-rural income gap significantly affects

970 environmental pollution through two channels: demand scale and human

971 capital. The inflection point of urban-rural income environmental

972 pollution between demand scale and human capital is located at 0.1307

973 and 0.3047 . This is also the main cause of the "inverted U-shaped" trend

974 of environmental pollution caused by the urban-rural income gap. Given

975 the potential spatial correlation of environmental pollution, the empirical

976 results of the spatial correlation model in this article show that after the

977 introduction of spatial correlation, the "inverted U-shaped" trend of

978 China's urban-rural income gap on environmental pollution is still

979 significant, with the inflection point at 0.2501 and geographical

980 proximity and the impact of the correlation on environmental pollution is 
981 also significant. Environmental regulations have a "positive U-shaped"

982 impact on environmental pollution through the income gap between

983 urban and rural areas, in other words, reasonable environmental

984 regulations can help improve the environment. However, excessive

985 environmental regulations will not help energy conservation and

986 emission reduction but may increase environmental pollution.

Therefore, this article has the following policy enlightenments to

988 deal with China's environmental pollution at this stage:

First, each region should choose the macro-control measures for the

990 urban-rural income gap that is appropriate to the region's characteristics

991 and that can maximize the local potential to ensure stable economic

992 growth and steady improvement of residents' lives while maximizing

993 energy conservation and emission reduction. The eastern region, regions

994 with high capital-labor ratios, and large cities' urban-rural income gaps

995 are already at a low overall position, but proactively adopting urban-

996 rural economic integration and promoting urban-rural integration can

997 still effectively alleviate environmental pollution; for the central and

998 western regions, low-capital-labor regions as for small and medium-sized

999 cities, the integration of urban and rural income may increase local

1000 pollution in the short term, and it is particularly important to establish a 
1001 governance system that coordinates industrial growth and environmental 1002 protection.

Second, relying on urban and rural income governance policies and

1004 scientifically combining market mechanisms to manage the local

1005 environment. In areas with low urban-rural income gaps, market

1006 consumption and basic education should be actively expanded, especially

1007 support and tilt for inclusive people's livelihood expenditures; in areas

1008 with high urban-rural income gaps, local industry status, resource

1009 endowments, etc. should be combined objective reality and reasonable

1010 promotion of consumption upgrades and human capital accumulation, to

1011 avoid excessive consumption and waste of resources.

1013 management system. In the process of urban-rural dualization and

1014 environmental pollution control, it is particularly critical to construct

1015 and improve the pollution control system from the perspective of

1016 regional characteristics. Therefore, effectively explore the pollution

1017 control effects of industry, urbanization, and environmental regulations,

1018 increase market-oriented construction, actively participate in and

1019 integrate the global production system, comprehensively promote

1020 infrastructure construction, encourage and guide financial development, 
1021 technological innovation, and other means that will pollute the region

1022 Governance is of great significance.

1023 Fourth, focus on the coordination of local governance and regional

1024 cooperation. The spatial relevance of environmental pollution requires

1025 that regions need to gradually get rid of the previous single local

1026 governance model and transform it into regional cooperative governance.

1027 Therefore, it is necessary to encourage the transition from regional

1028 competition to regional cooperation, eliminate regional administrative

1029 barriers and local protectionism, and promote regional Inter-industry

1030 collaboration and integration, and integration of regional factor markets

1031 to improve resource efficiency.

1032

1033 Corresponding authors:

1034 Wei-wei He, Ph.D.

1035 School of Economics and Trade,

1036 Hunan University,

1037 Changsha 410006, Hunan, China.

1038 Email: 124039791@qq.com 
1040 Acknowledgements:

1041 None declared to all authors. The responsibility for any errors rests

1042 solely with the authors.

1043

1044 Funding:

1045 The authors are grateful for financial support from the major project of

1046 the National Social Science Foundation of China (Grant No. 17ZD099).

1048

1049 Availability of data and materials:

1050 The data on the quality of export products in the article comes from the

1051 China Customs Database, and the data on the control variables at the

1052 enterprise level comes from the Database of Chinese Industrial

1053 Enterprises.

1054

1055 Competing interests: 
1056 The authors declare that they have no competing interests.

1057

1058 Consent to publish:

1059 This manuscript does not contain data from any individual person.

1060

1061 Ethics approval and consent to participate:

1062 There is no human participants, human data or human tissue involved in 1063 the manuscript.

1065 Author contribution:

1066 Conceptualization: Wei-wei He,

1067 Data curation: Keke Cheng.

1068 Investigation: Wei-wei He

1069 Methodology: Wei-wei He

1070 Supervision: Junjun Hou.

1071 Writing - original draft: Wei-wei He.

1072 Writing - review \& editing: Junjun Hou. 


\section{References}

Boyce, J.K., (1994). Inequality as a Cause of Environmental Degradation.

Ecological Economics,11 (3),169-78.

1079 Modelling,40(C),33-40.

Baek, J., \& Gweisah, G., (2013).Does income inequality harm the

environment? Empirical evidence from the United States. Energy Policy,

Protection Policy and Income Distribution. Ecological Economics, 32(3),431-443. $65(2), 375-85$. 
1091 trading, and environmental protection. Rivista Di Politica Economica ,1(99),127-

1092144

1093

1094

1095

1096

1097

1098 1099 induced Innovations. Review of Economic Studies,73(4), 941-960.

1100

1101

1102

1103

1104

1105

1106

1107

1108

Chao,X., \& Shen, K.,(2014).Urban-Rural Income Disparity, Labor Quality and Economic Growth in China. Economic Research, Issue 6, pp. 30-43.

Feng, H., \& Fang, Y.,(2014). Environmental Effects of Fiscal Expenditure at the Local Level: An Empirical Investigation from Cities in China. Financial and Trade Economics, Issue 2, pp. 30-43.

Foellmi, R., \& Zweimüller, J., (2006). Income Distribution and Demand-

Ghalwash, M.T., (2008). Demand for environmental quality: an empirical analysis of consumer behavior in Sweden. Environmental \&Resource Economics, 41,71-87.

Goetz, S.J., \& Debertin, D.L.,(1997).Linkages between human capital and the environment: implications for sustainable economic development. Occasional Paper Series (7),337-344.

Grossman, G., \& Kruegger, A.(1991). Environmental Impacts of a North American Free Trade Agreement. NBER Working Paper, No.3914.

Gao, F., \& Wang, Y.,(2016). How Does the Urban-Rural Income Gap Affect Total Factor Productivity? Research on Quantitative Economics and Technical 
1112 Analytical Comparison between Developing Economies and Developed

1113 Economies. International Trade Issues, Issue 9 pp. 76-85.

1117 Population Density, Economic Agglomeration and Carbon Emission State of

1118 Chinese Province: Based on the Perspective of Agglomeration Economy Effects,

1119 Congestion Effects and Spatial Effects. Nankai Economic Research, Issue 2, 1120 pages 207-225.

1122 Investment Inflows to the U.S. States. Review of Economics and Statistics, 84

1123 (4), 691-703.

1125 Urban Productivity. Economic Research, Issue 4, pp. 76-88. 
1130 export products: Comparison of the transmission mechanism and choice of

1131 optimization direction based on multinational data, Issue 1, pp. 14-24.

1132 Lv, L., \& Gao, H.,(2005). Analysis of the Environmental Effects of my

1133 country's Regional Income Gap. China Soft Science, Issue 4, pp. 105-111.

1134 Li, T., \& Fu, Q.,(2011). Study on China's Carbon Dioxide Emissions

1135 Efficiency. Statistical Research, Issue 7, pp. 62-71.

1136 Lan, J., \& Munro, A.,(2013). Environmental compliance and human capital:

1137 Evidence from Chinese industrial firms. Resource \&Energy Economics,

$113835(4), 534-557$.

1139 Li, Z., \& Zhu, J.,(2014).A study on the mechanism of distribution to demand

1140 and innovation: A consumer demand perspective. Science Research, Issue 12, pp.

1141 1897-1908.

1142 Liu, D., \& Shen, K.,(2012). Factor Distribution, Resident Income Gap and

1143 Consumption Growth. Quantitative Economics and Technical Economics

1144 Research, Issue 10, pp. 47-52.

1145 Li, P., Li, S., \& Xu, J.,(2012). Income Gap, Effective Demand, and

1146 Independent Innovation. Financial Research, Issue 2. pp. 16-26.

1147 Lu, H., Du, Y., \& Qi, Y.,(2015). Fiscal Expenditures in China and 
1148 Consumption-generated Pollution: Theoretical Model and Empirical Test. China

1149 Population, Resources, and Environment, Issue 10, pp. 61-70.

1150 Lu, W., Yang, M., \& Wang, Y.,(2015). The Urban-Rural Income Gap and

1151 Education Inequality and Government Spending on Education in China.

1152 Comparison of Economic and Social Systems, Issue 3, pp. 20-33.

1153 Liu, Q., Wang, S., Zhang, W.,\& Li, J.,(2018). Income distribution and

1154 environmental quality in China: A spatial econometric perspective. Journal of

1155 Cleaner Production, 205(20),14-26.

1161 Markusen, J.R., \& Venables, A.J.,(1999). Foreign direct investment as a

1162 catalyst for industrial development, European Economic Review, 43 (2),335-356. Ma, Z., Pan, Z., \& He, H.,(1999). GREENHOUSE GAS EMISSION FACTOR 
1168 Disparity and CO2 Emissions from Household Consumption. Journal of Beijing

1169 Institute of Technology (Social Science Edition), Issue 6, Pages 1-9.

1170 Nico, H., Abay, M., \& Erwin, B.,(2001). Income inequality and the

1171 environment: aggregation bias in environmental Kuznets curves. Ecological

1172 Economics,38(3), 359-367.

1173 Panayotou, T., (1993). Empirical Tests and Policy Analysis of Environmental

1174 Degradation at Different Stages of Economic Development. ILO Working Paper's,

1175 NO.9.

1177 Perspective of Income Distribution-—Based on Time Series Data Analysis from

11781986 to 2008. Forum on Science and Technology in China, Issue 6, Issue 94 -98

1179 pages.

Scruggs L.A.,(1998). Political and Economic Inequality and the Environment.

1181 Ecological Economics, 26 (3),259-75.

1183 Spillover, and Endogenous Economic Growth: An Econometric Test and Empirical 1184 Analysis of Chinese Data. Chinese Social Sciences Issue 5 pp, 82-93.

1185 Song, D., \& Yang, Q.,(2019). The Role of Environmental Regulation and 

human capital agglomeration on industrial structure upgrading: an empirical study

1194 Location-Oriented Industrial Policies: An Empirical Study Based on Development 1195 Zone Policies. Chinese Social Sciences, Issue 12, pp. 48-68.

1197 Energy Saving and Emission Reduction: Theory and Empirical Evidence from

1198 China. Management World, Issue 11, pages 36-60. 
1206 Environmental Technologies. Ecological Economics,70(11), $2201-2213$.

1211 Environmental Pollution? Spatial Measurement Research Based on China's Inter-

1212 provincial Panel Data. Management World, Issue 2, pp. 30-43.

1215 Finance and Economics, Issue 1, Pages 16-21. empirical test based on provincial panel data. Journal of Yunnan University of 
1224 environmental quality? Analysis based on China's provincial panel data.

1225 Ecological Indicators, 67(8),533-542.

1227 structure on regional carbon emission: Empirical evidence across countries.

1228 Geographical Research, Issue 1, pp. 82-94.

1231 from the perspective of resource curse. China Population, Resources, and

1232 Environment, Issue 5, No. 52 -60 pages.

1234 Impact of Inequality on Innovation-driven Growth, Journal of Economic Growth, $12355(2), 185-206$.

1237 from China' s CO2 Emission. Nankai Economic Research No. 6, 126-139.

1238 Zhan,H.,(2018). The Effect of Income Inequality on Environmental Pollution:

1239 Reassessment of the Environmental Kuznets Curve of China. Economic Review,

1240 Issue $6 \mathrm{pp}, 100-112$.

1241 Zhang, L., \& Li, J.,(2016). Theoretical Relationship and Empirical Analysis of 1242 Income Distribution and Economic Growth. Management World, Vol. 11, pp. 1-10. 
1244 Cities. Economic Research, Issue 9, pp. 84-95.

1245 Zhong, M., \& Zhao, Z.,(2013).Does Urban - rural Income Gap Aggravate

1246 Environmental Damage? An Empirical Research Based on China's Provincial

1247 Panel Data. Economic Jingwei, Issue 3, pp. 125-128.

1249 emissions: A regional analysis in China. Applied Energy, 136(C), 382-392.

1250 Zhu, Q., Peng, X., \& Wu, K.,(2012). Analysis of Changes in Energy-carrying

1251 Carbon Emissions of Consumer Goods Based on Structural Decomposition.

1252 Quantitative Economics and Technical Economics Research, Issue 1, pp. 65-77.

1253 Zhang,T., Yang, J., \& Sheng, P.,(2016). The Impacts and Channels of

1254 Urbanization on Carbon Dioxide Emissions in China. China Population,

1255 Resources, and Environment, Issue 2, pp. 47-57. 